\title{
O plano educacional individualizado em contexto de pandemia
}

Caroline Menezes Nunes de Oliveira ${ }^{1}$ Priscila Rodrigues Cruz Francisco ${ }^{2}$

\begin{abstract}
Resumo:
Este trabalho propõe-se a apresentar um relato de experiência viabilizado pelo curso de extensão "Alfabetização e letramento para estudantes com deficiência intelectual sob o viés do plano educacional individualizado", da Universidade do Estado do Rio de Janeiro - UERJ. Dessa forma, o estudo se dividirá, primeiramente, em uma fundamentação teórica baseada em leis federais e em Mascaro (2017; 2018; 2020a; 2020b; 2021), seguindo para a apresentação do protocolo utilizado, e, finalmente, apresentará o referido relato. Importante pontuar que, inicialmente, a proposta não contemplava a aplicação remota, entretanto, devido às condições decorrentes da pandemia ocasionada pelo vírus COVID-19 no Brasil, em 2020, houve a necessária adaptação e, consequentemente, o ineditismo da aplicação de um Plano Educacional Individualizado (PEI), mesmo com a suspensão das aulas presenciais e isolamento social. A aplicação descrita no presente trabalho possibilitou ao sujeito a ampliação dos seus conhecimentos em relação à leitura e escrita através das tecnologias da informação e comunicação, aproximando o indivíduo de instrumentos culturais da cibercultura, em que se objetivou também a inclusão laboral e social. Em suma, destaca-se uma considerável contribuição para estudos e intervenções futuras, em momentos educacionais críticos ou não.
\end{abstract}

\section{Palavras-chave:}

Plano educacional individualizado (PEI). Deficiência intelectual. Pandemia.

\section{Individualized educational plan in pandemic}

\begin{abstract}
:
This work proposes to present an experience report made possible by the extension course "Initial reading instruction and literacy for students with intellectual disabilities under the bias of the individualized educational plan" from the State University of Rio de Janeiro. In this way, the study will be divided, firstly, into a theoretical foundation based on federal laws and Mascaro (2017; 2018;

1 Graduada em Psicologia. Graduanda em Pedagogia pela Universidade do Estado do Rio de Janeiro - UERJ -, Bolsista de Iniciação Científica, CNPq. E-mail: cmnunesoi@gmail.com. ORCID iD: https://orcid.org/0000-0002-7966-850X.

2 Graduada em Pedagogia. Pós-Graduanda em Psicopedagogia pela Universidade do Estado do Rio de Janeiro -UERJ. Mestranda pelo Programa de Pós-Graduação de Ensino em Educação Básica - CAp-UERJ. Professora da Rede Pública Municipal do Rio de Janeiro. E-mail: priscila.rcruz@rioeduca.net. ORCID iD: https://orcid.org/0000-0002-6626-6632.
\end{abstract}


2020a; 2020b; 2021), followed by the presentation of the protocol used, and finally, it will present the aforementioned report. It is important to point out that, initially, the proposal did not contemplate remote application, however, because of the conditions resulting from the pandemic caused by the COVID-19 virus in Brazil in 2020, there was the necessary adaptation and, consequently, the unprecedented application of an individualized educational plan (IEP) even with the social isolation. The application described in the present work enabled the subject to expand his knowledge concerning reading and writing through information and communication technologies, bringing the subject closer to cyberculture, in which work and social inclusion were also aimed. In short, there is a considerable contribution to future studies and interventions, in critical educational moments or not.

\section{Keyword:}

Individualized educational plan. Intellectual disability. Pandemic.

\section{Programa educativo individualizado en la pandemia}

\section{Resumen:}

Éste trabajo propone presentar un relato de experiencia hecho posible por el curso de extensión "Alfabetización e instrucción para estudiantes con discapacidad intelectual bajo el sesgo de la individualización plan educativo" de la Universidade Estadual do Rio de Janeiro - UERJ. El estudio se dividirá primero en un fundamento teórico basado en leyes federales y Mascaro (2017; 2018; 2020a; 2020b; 2021), finalmente presentando el informe. Es importante señalar que inicialmente la propuesta no contempló la aplicación remota, sin embargo, debido a las condiciones derivadas de la pandemia causada por el virus COVID-19 en Brasil en 2020 era necessario una adaptación y como consecuencia la novedad de la aplicación sin precedentes de um individualización plan educativo (PEI) incluso con la suspensión de las clases presenciales. La aplicación descrita en el presente trabajo permitió al sujeto ampliar sus conocimientos en relación a la lectura y la escritura utilizando las tecnologías de la información y la comunicación, acercando el tema a los instrumentos culturales de la cibercultura, en los que también se apuntó al trabajo y la inclusión social. En definitiva, hay un aporte considerable para futuros estudios e intervenciones, en momentos educativos críticos o no.

\section{Palabras clave:}

Programa educativo individualizado. Discapacidad intelectual. Pandemia.

\section{Introdução}

De acordo com a Lei de Diretrizes e Bases da Educação Nacional, LDB (BRASIL, 1996), os sistemas de ensino deverão assegurar currículos, métodos, técnicas, recursos educativos e organização específicos, para atender às necessidades dos educandos com deficiência, transtornos globais do desenvolvimento e altas habilidades ou superdotação. Outro aparato legal encontra-se na Lei Brasileira de Inclusão, LBI (BRASIL, 2015), que estabelece planejamento de estudo de caso, de elaboração de plano de atendimento educacional especializado, de organização de recursos e serviços de acessibilidade e de disponibilização e usabilidade pedagógica de recursos de tecnologia assistiva. Dessa forma, os alunos público-alvo da educação especial são respaldados legalmente para um processo de ensino-aprendizagem significativo, mas ainda assim é possível observar a falta de diálogo entre esses documentos e a prática realizada em instituições educacionais.

Diante de tantos desafios e necessidade de personalização dos processos de educação escolar, legitimada pelas leis citadas, o plano educacional individualizado - PEI - emerge na conjuntura 
escolar como facilitador e possibilitador de todo o processo em diversos estudos, como de Pletsch e Glat (2012), Pereira (2014), Mascaro (2017; 2018) e Fontana, Cruz e De Paula (2019). O PEI é um mecanismo fundamental para "[...] garantir os resultados esperados do processo de escolarização de pessoas em situação de deficiência” (TANNÚS-VALADÃO, 2013, p. 53 Apud MASCARO, 2017, p. 45), seja em escolas ou classes especiais ou em turmas de ensino comum (TANNÚS-VALADÃO, 2013 Apud MASCARO, 2017).

E, por que não adotá-lo na modalidade de ensino remoto emergencial, momento de maior necessidade como o ocasionado pela COVID-19? Mas, diante de tantos entraves e desafios, seria possível tal abordagem? Como?

\section{Reflexões teóricas: subsídios para a prática}

Antes de adentrar nessa perspectiva, faz-se necessária a abordagem de questões primárias. A princípio, vale ressaltar que diversas nomenclaturas são encontradas na Literatura, como: plano de ensino individualizado (PEI), plano educacional individualizado (PEI), plano de desenvolvimento individual (PDI) e plano de atendimento individualizado (PAI) para o documento em si e planejamento de ensino individualizado (PEI) ou planejamento educacional individualizado (PEI) quando se refere a qualquer tipo de planejamento voltado para alguma personalização dos processos de educação como a adequação curricular.

Grande parte das obras literárias trazem essas denominações como sinônimos. Este estudo continuará considerando PEI (plano educacional individualizado e derivações) e PDI (plano de desenvolvimento individualizado) como símile de significado, levando em consideração toda revisão bibliográfica relevante, sem distinção entre ambos.

Resumidamente, Mascaro (2021) coloca que o PEI é um plano de personalização dos processos de ensino. Já Glat, Vianna e Redig (2012), Mascaro (2017) e Hudson e Borges (2020) conceituam o PEI como:

[...] planejamento individualizado, periodicamente avaliado e revisado, que considera o aluno em patamar atual de habilidades, conhecimentos e desenvolvimento, idade cronológica, nível de escolarização já alcançado e objetivos educacionais desejados em curto, médio e longo prazos (GLAT; VIANNA; REDIG, 2012, p. 84 Apud MASCARO, 2017, p. 44).

Muitos dos planos individualizados apresentam estruturas diferentes, mas há questões que podem ser observadas na maioria deles, como: “[...] nome, idade, quanto tempo está na escola, aprendizagens já consolidadas, dificuldades encontradas, objetivos para este aluno, metas e prazos, os recursos ou adaptações curriculares utilizadas e os profissionais envolvidos na elaboração do plano" (GLAT; VIANNA; REDIG, 2012, p. 85). Porém, independentemente de sua estruturação, o PEI visa a garantir a acessibilidade do aluno ao currículo. Contudo, ele vai além, porque articula com o projeto pedagógico da escola, subsidiando a proposta educacional, além de abranger os planejamentos pedagógicos, os processos para implementação das atividades e a correção de rumos.

Porém, ainda assim, a dificuldade de estruturação de um plano educacional individualizado é latente no universo docente. As secretarias municipais e estaduais oferecem modelos de elaboração para suas regiões, mas se faz necessária a reflexão do professor: será que existe algum outro "modelo" que poderia ser mais conveniente a tal caso específico ou que ofereça maiores contribuições ao já utilizado? Ou que possibilite maiores adequações segundo as realidades e elucida melhor o caminho que será percorrido? Enfim, mais simples, claro e objetivo, que conduza no como proceder? Mascaro (2020a) oferece um caminho para elaboração do PEI, uma proposta de passo a passo que se constitui em um protocolo. 


\section{Metodologia: o Protocolo Mascaro}

Segundo o Instituto Brasileiro de Geografia e Estatística, IBGE (2021), a Pesquisa Nacional por Amostra de Domicílios Contínua (PNAD Contínua), de 2019, aferiu que cerca de onze milhões de brasileiros são analfabetos. Presume-se que uma parte desse público seja de pessoas com deficiência intelectual, pela dificuldade de acesso e permanência na escola marcadas na história dessa camada populacional. O Protocolo Mascaro (2020b) tem como eixo a alfabetização e o letramento para estudantes jovens e adultos com deficiência intelectual sob o viés do plano educacional individualizado, mas pode e deve ser adequado conforme as necessidades e realidade do sujeito. A importância desse foco soma-se à grande relevância da alfabetização e do letramento para a inclusão social de qualquer pessoa frente às oportunidades e autonomia geradas por tal.

Para tanto, o Protocolo Mascaro (2020b) propõe o caminho representado na figura a seguir:

Figura 1: Protocolo do PEI

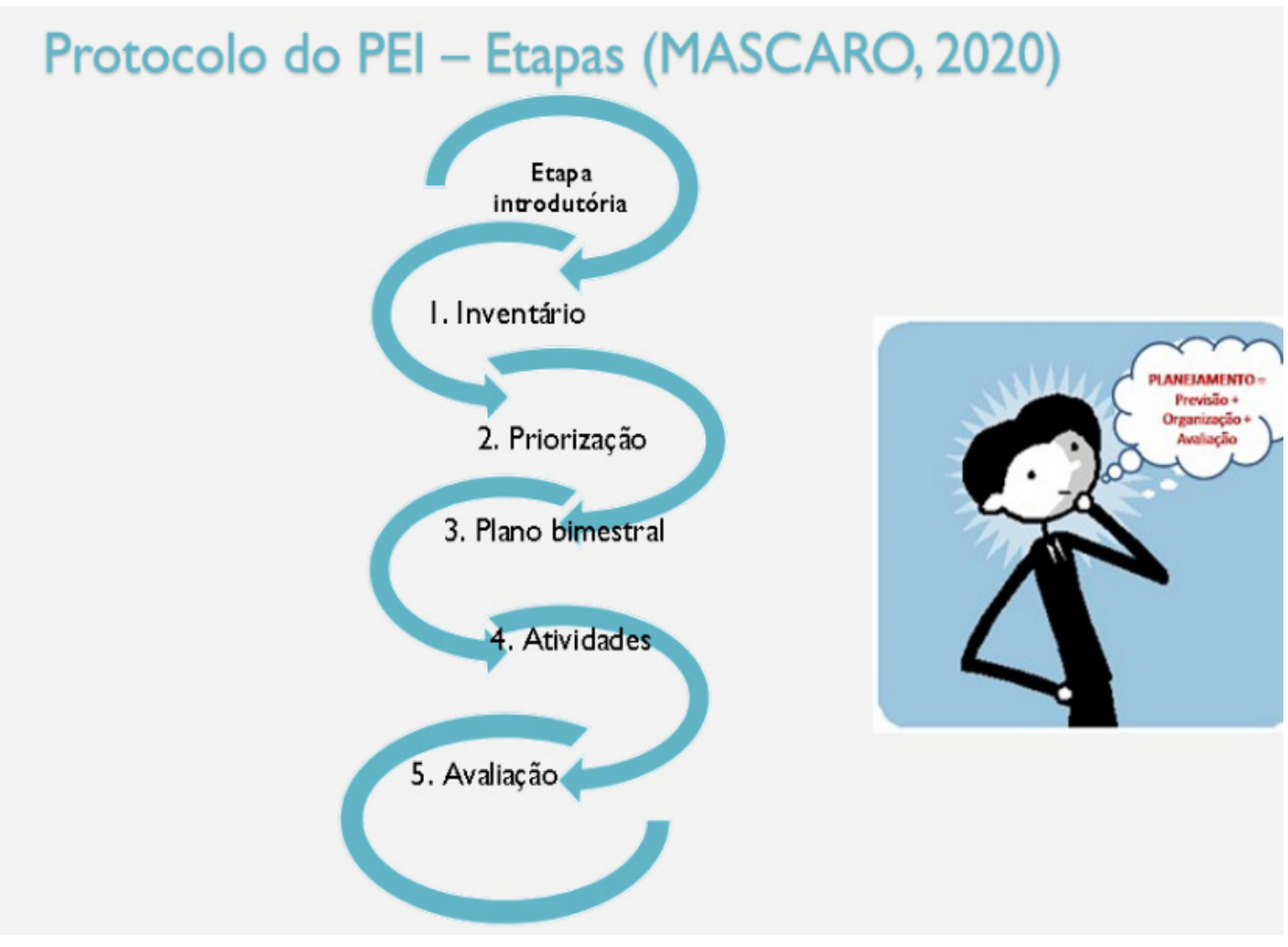

Fonte: Mascaro (2021).

Dessa forma, o PEI pode ser dividido em: etapa introdutória, e mais cinco etapas: 1 - Inventário; 2 - Priorização; 3 - Plano Bimestral; 4 - Atividades e 5 - Avaliação.

A etapa introdutória consiste no levantamento de dados preliminares para a elaboração do PEI. Nessa etapa, o foco é elaborar um perfil do estudante. E, para tanto, é realizada uma pesquisa (podendo colher os dados por meio de entrevista com responsável ou profissional da instituição de ensino ou por consulta a documentos pedagógicos relevantes). Vale ressaltar que, quando possível, a entrevista com o próprio aluno é de grande valia.

A etapa 1 - o Inventário - refere-se ao preenchimento do Inventário Avaliativo de Habilidades, composto por quatro grandes grupos (aquisição do sistema de escrita, leitura, escrita e produção de textos e alfabetização matemática) divididos em 22 habilidades. A partir disso, verificam-se as 
habilidades em maior carência. Ressalta-se que esse Inventário busca identificar as necessidades específicas de aprendizagem para subsidiar o planejamento do trabalho pedagógico nas áreas da Comunicação Oral, Leitura e Escrita e Raciocínio Lógico Matemático, mas cabem adaptações.

Na etapa 2 - a Priorização -, com base no resultado do Inventário Avaliativo de Habilidades, realiza-se a priorização das habilidades a serem desenvolvidas.

A etapa 3 - o Plano bimestral - diz respeito ao estabelecimento das metas. Recomenda-se que seja realizado o plano bimestral ou trimestral, definindo as metas bimestrais ou trimestrais.

A etapa 4 - as Atividades - consiste em descrever o cotidiano dos atendimentos pedagógicos, incluindo a seleção de recursos e planejamento. É importante registrar de forma descritiva as observações. É um diário de campo (avaliação da proposta, dificuldades encontradas, algumas ideias futuras para o trabalho). Também é recomendado registrar algumas notas de campo com as reflexões sobre o trabalho realizado. Assim, permite-se uma avaliação mais detalhada do desempenho do estudante, como bem elucida Mascaro (2020a, p. 26) que "[...] o PEI surge como um instrumento que balizará o itinerário formativo do aluno. A retenção ou promoção vai estar sempre em consonância com avaliação do PEI".

Já a etapa 5 - a Avaliação -, faz parte de todo o processo; inclusive, por isso, já foi citada anteriormente. $O$ percurso para a aplicação do plano educacional individualizado demanda $o$ olhar avaliativo em todas as etapas, pois, como elucida Mascaro (2017):

A avaliação é um instrumento de grande relevância no trabalho do professor, pois tem a função de proporcionar esclarecimentos sobre o que o aluno aprendeu ou não, podendo assim refletir sobre a metodologia utilizada para ensinar, melhorando sua prática e a aprendizagem do aluno. Temos que considerar que quando o aluno não aprende, pode ser que, os recursos e estratégias que não foram adequados para a forma como ele se apropria e constrói conceitos. Por isso, é tão importante a avaliação processual em todas as etapas relacionadas ao ensino, permitindo o desenvolvimento de práticas pedagógicas adequadas às necessidades de aprendizado do aluno (MASCARO, 2017, p. 121).

De todo modo, a grande questão do Protocolo é a flexibilidade pelas possibilidades de adequações, pois a proposta de "Alfaletramento" (SOARES, 2020) no Protocolo visa a incorporar ações pedagógicas personalizadas para a inclusão social, inclusão escolar, inclusão laboral, ou seja, inclusão para a vida. Além do mais, sua estruturação também permite adequações para diferentes faixas etárias, independentemente do tipo de deficiência ou transtorno.

Após o todo aqui já abordado e apesar de toda relevância, ainda permanece a grande questão: mas seria possível colocar o Protocolo Mascaro (2020b) em prática durante a pandemia? Mesmo com a suspensão das aulas e o isolamento social?

\section{0 relato de experiência: uma nova possibilidade}

Com a finalidade de responder os questionamentos anteriores, apresenta-se o relato de experiência, que é um desdobramento do curso de extensão "Alfabetização e letramento sob o viés do Plano Educacional Individualizado - PEI” (MASCARO, 2020a), da Universidade do Estado do Rio de Janeiro - UERJ - realizado no ano de 2020.

Inicialmente, o curso seria realizado de forma presencial, no entanto, devido ao cenário pandêmico ocasionado pela COVID-19, foi necessária a mudança para a modalidade remota e reformulação da proposta inicial. Diante dessa nova dinâmica, a aplicação do Plano Educacional Individualizado à distância foi possibilitada. Contudo, antes da prática propriamente dita, os aplicadores receberam formação teórica, orientação e supervisão do caso durante o processo. 
A escolha do sujeito ocorreu ainda durante o curso. O jovem, na época, ingressava no mundo empregatício. A partir da necessidade do sujeito de ser inserido no mercado de trabalho, e consequentemente as questões de alfabetização e letramento emergirem nessa nova fase, o indivíduo e sua família aceitaram participar do processo. Com a confirmação do interesse, iniciou-se a construção do plano que seguiu as cinco etapas (Figura 1) do protocolo de Mascaro (2020b): inventário avaliativo; planejamento de priorização de habilidades; planejamento bimestral ou trimestral do PEI; planejamento de atividades e avaliação e replanejamento, se necessário.

Antes da aplicação com o aluno, era necessário realizar a etapa introdutória, segundo o Protocolo. E, para tanto, foram realizadas reuniões com as profissionais envolvidas em seu processo educacional, o sujeito e a mãe. A partir das informações obtidas, foi possível preencher o inventário e planejar as atividades.

Após esse processo e avaliação do caso, o grupo ${ }^{4}$ decidiu que a indicação do planejamento seria para inserção ou manutenção no mercado de trabalho, uma vez que o sujeito em questão tinha acabado de conseguir um emprego. E o objetivo traçado foi desenvolver atividades que favorecessem a construção da leitura e escrita, alinhando as necessidades do cotidiano laboral e atividades sociais do indivíduo. Então, a partir disso, foram elaboradas quatro possíveis atividades para serem realizadas com o sujeito.

A aplicação de forma remota sucedeu nos meses de novembro e dezembro de 2020, com dois encontros semanais, que tinham duração de trinta a quarenta minutos. Primeiramente, ocorriam pela Plataforma Zoom ${ }^{5}$, pois era a mesma utilizada pelo curso. Entretanto, no decorrer de dois encontros, foi perceptível a dificuldade na utilização dessa plataforma, uma vez que ela não apresenta uso muito intuitivo. Dessa forma, foi necessária a migração para o Google Meet ${ }^{6}$.

Para a realização das atividades, também foi verificada a necessidade de mudança do Word $^{7}$ para o Google Forms ${ }^{8}$, já que essa segunda plataforma apresentou uma gama maior de recursos. A justificativa se dá pelo fato de o Google Forms ser uma plataforma online gratuita, ou seja, não gera custo para nenhuma das partes, diferentemente do Word, que é um software pago. Além disso, para o sujeito responder uma questão no Word, era disposta pela equipe uma linha em que indicava onde deveria colocar a sua resposta digitando. No entanto, ao digitar, a linha se deslocava para o lado e isso, de uma certa maneira, ficava esteticamente desagradável e desconfigurava a página, dificultando a execução da atividade. Ao contrário do software, o Google Forms gera automaticamente uma linha que indica onde deve ser colocada a resposta e ela se mantém, simulando a mesma dinâmica de uma folha de papel onde a escrita é realizada tendo a linha como base.

Nos primeiros encontros, os períodos mais longos foram destinados para adaptação à plataforma, tanto para o grupo como para o sujeito e a mãe. Assim que as ferramentas foram fixadas, foi realizada a orientação tecnológica para os dois, uma vez que não estavam adaptados com tais meios digitais. Pode-se afirmar que essa orientação foi muito maior para a mãe do que para o próprio sujeito, visto que se apresentava muito disperso no dado momento. Ressalta-se que durante esse período as atividades planejadas também estavam sendo aplicadas, ou seja, era separado um tempo para a orientação tecnológica e outro para a realização de tais atividades planejadas.

Para a aplicação bimestral, foram planejadas quatro atividades, porém apenas três foram utilizadas, em que foi priorizada a necessidade do indivíduo devido à escassez de tempo. A exemplificar, será apresentada a atividade que foi realizada no dia treze de novembro de 2020 (Figura 2).

\footnotetext{
4 Grupo de aplicadoras: Caroline Nunes, Maria Regina Menezes e Neuzilene Burock.

5 Plataforma de reuniões por videoconferência online desenvolvida pela Zoom Vídeo Communications.

6 Plataforma de reuniões por videoconferência online desenvolvida pela Google.

7 Processador de texto produzido pela Microsoft Office.

8 Plataforma de gerenciamento de pesquisas desenvolvida pela Google que pode ser usada também para registro de formulários e questionários.
} 
Figura 2: Planejamento da atividade

\begin{tabular}{|c|}
\hline PEI n 01 - Periodicidade das atividades: Semanalmente \\
\hline Participante: João (nome fictício) \\
\hline Pesquisador/professor: Caroline Nunes, Maria Regina Menezes e Neuzilene Burock. \\
\hline Atividadeno: $2 \quad$ Vigência do PEl: dois meses \\
\hline $\begin{array}{l}\text { Data: } 13 / 11 / 2020 \\
\text { Local: Google Meet }\end{array}$ \\
\hline $\begin{array}{l}\text { Habilidades: Aquisição do sistema de escrita (1. Compreensão das diferenças existentes entre os sinais } \\
\text { do sistema de escrita alfabético-ortográfico e outras formas gráficas e sistemas de representação) e } \\
\text { leitura (9. Identificação de diferenças entre gêneros textuais). }\end{array}$ \\
\hline $\begin{array}{l}\text { Objetivos: Distinguir as letras de imprensa maiúscula e minúscula, e a cursiva, maiúscula e minúscula; } \\
\text { trabalhar identidade. }\end{array}$ \\
\hline $\begin{array}{l}\text { Descrição da atividade: } \mathrm{A} \text { atividade será realizada a partir do formulário do Google Forms < } \\
\text { https://docs.google.com/forms/d/e/1FAlpQLSdnwrh_KWaXISrveCKabmive_G3KGeEgv2mJkCLW3CXZ } \\
\text { SoGEg/viewform>. Nele utilizaremos a certidão de nascimento e a identidade do sujeito para que ele } \\
\text { primeiro entenda a função do documento para depois explorar as informações que contém nele. A } \\
\text { partir dessas informações iremos trabalhar a escrita, primeiramente com o apoio, idealizando retirá- } \\
\text { lo, e depois a compreensão do documento através de perguntas objetivas. Ao final do encontro } \\
\text { reproduziremos um vídeo de música do interesse do sujeito com o intuito de trabalhara linguagem e } \\
\text { o gênero musical. }\end{array}$ \\
\hline
\end{tabular}

Fonte: Elaborado pelas autoras.

Nesse dia, foi trabalhada a identidade para o exercício da cidadania, aproveitando que as eleições estavam se aproximando e mostrando ao sujeito a função social do documento. Anteriormente, foi trabalhada a função do prefeito e do vereador na cidade e o que deve ser utilizado no dia para a votação.

A atividade descrita, então, tinha como objetivo trabalhar a identidade e a certidão de nascimento a partir do documento do próprio sujeito e recapitular as orientações para o dia das eleições. Antes dessa dinâmica, foi solicitado à mãe enviar a identidade e a certidão de nascimento para a realização das atividades com base nos documentos. A partir disso, foi elaborado um documento no Google Forms com as informações da identidade: nome completo, nome do pai, nome da mãe e data de nascimento. A utilização da identidade foi essencial para que o sujeito consultasse, marcasse ou completasse a atividade. Nesse dia, ele e a mãe compartilharam a tela e, ao invés de ser realizada a cópia do que o sujeito estava escrevendo no chat, para então colar no formulário, como estava acontecendo anteriormente, o próprio aluno escreveu no formulário, com as aplicadoras do PEI acompanhando e auxiliando, caso fosse necessário. Ao final, foi recapitulado que, para o exercício pleno da cidadania, é preciso atuar na sociedade e que a eleição é uma ótima oportunidade para isso. Logo após, de acordo com o interesse do aluno, foi separado um momento em que o aluno escolheu algo que todos deveriam fazer, o que resultou no canto de sua música preferida.

Ressalta-se que esse encontro, assim como todos os que ocorreram nos dois meses, só foram possíveis, não apenas pelo comprometimento do grupo e do sujeito, mas também de sua mãe, que atuou de forma singular durante as aplicações. Sem ela a prática seria inviabilizada. No entanto, o objetivo também é que, com o decorrer do tempo, o estudante adquira autonomia nos meios digitais e não necessite do auxílio de uma mediação.

Dessa forma, foi possível identificar, após o tempo de aplicação, que o sujeito, além de se interessar mais pela sua independência e individualidade, começou a ter mais familiaridade com o computador e melhorou a correspondência da letra bastão maiúscula do teclado com a minúscula que aparecia quando ele digitava. Outro ponto positivo dessa experiência foi a da cidadania sendo exercida no dia das eleições de 2020.

Portanto, de acordo com Santos (2020, p. 29), “[...] a pandemia e a quarentena estão a revelar que são possíveis alternativas, que as sociedades se adaptam a novos modos de viver quando tal é necessário e sentido como correspondendo ao bem comum". Desse modo, o relato descrito foi o resultado da necessidade de adaptação diante do cenário pandêmico que possibilitou novas formas de aplicação para o plano educacional individualizado. 


\section{Considerações finais}

A aplicação descrita no presente trabalho possibilitou ao sujeito a ampliação dos seus conhecimentos em relação à leitura, escrita e letramento matemático nos meios tecnológicos, objetivando o seu desenvolvimento laboral, visto que havia acabado de ingressar no mercado de trabalho. Além disso, houve considerável interesse do estudante em desenvolver sua autonomia e independência. Dessa forma, recomenda-se que os aplicadores valorizem as necessidades e os interesses do sujeito para que assim a prática tenha sentido para o indivíduo.

Com o todo aqui apresentado, conclui-se que a aplicação relatada, provocada pelo cenário pandêmico, apresentou a possibilidade de o plano educacional individualizado ser ofertado de forma remota, explicitando que práticas educacionais com resultados significativos podem ocorrer através das tecnologias da informação e comunicação. Ademais, percebe-se considerável contribuição para estudos e práticas futuras.

\section{Referências}

BRASIL. Congresso Nacional. Lei n 1.3146 de 2015. Lei Brasileira de Inclusão da Pessoa com Deficiência. Brasília, DF, 2015.

BRASIL. Lei no 9.394 de 1996, de 20 de dezembro de 1996. Diretrizes e Bases da Educação Nacional. Estabelece as diretrizes e bases da educação nacional. Diário Oficial da União. Brasília, DF, 23 dez. 1996.

FONTANA, Evelline Cristhine; CRUZ, Gilmar de Carvalho; PAULA, Luana Aparecida de. Plano educacional individualizado: uma estratégia de inclusão e aprendizagem nas aulas de Educação Física. Da Investigação às Práticas. Lisboa, v. 9, n. 2, p. 118-131, 2019.

GLAT, Rosana; VIANNA, Márcia Marin; REDIG, Annie Gomes. Plano Educacional Individualizado: uma estratégia a ser construída no processo de formação docente. Ciências Humanas e Sociais em Revista. Rio de Janeiro, v. 34, n. 12 , p. 79-100, 2012.

HUDSON, Bruna Cristina da Silva; BORGES, Adriana Araújo Pereira. A utilização do Plano de Desenvolvimento Individual por professores em Minas Gerais. Revista Educação Especial.v. 33, 2020. Disponível em: https://periodicos. ufsm.br/educacaoespecial/article/view/47967/html. Acesso em: 13 mar. 2021.

IBGE. Instituto Brasileiro de Geografia e Estatística. Conheça o Brasil - População: Educação, 2021. Disponível em: https://educa.ibge.gov.br/jovens/conheca-o-brasil/populacao/18317-educacao.html. Acesso em: 13 abr. 2021.

MASCARO, Cristina Angélica Aquino de Carvalho. O atendimento pedagógico na sala de recursos sob o viés do plano educacional individualizado para o aluno com deficiência intelectual: um estudo de caso, 2017. Tese (Doutorado em Educação) - Faculdade de Educação, Universidade do Estado do Rio de Janeiro, Rio de Janeiro, 2017.

MASCARO, Cristina Angélica Aquino de Carvalho. O Plano Educacional Individualizado e o estudante com deficiência intelectual: estratégia para inclusão. Revista Espaço Acadêmico, n. 205, jun. 2018. Disponível em: http://periodicos. uem.br/ojs/index.php/EspacoAcademico/article/view/43318. Acesso em: 16 jan. 2021.

MASCARO, Cristina Angélica Aquino de Carvalho. Alfabetização e Letramento para Estudantes com Deficiência Intelectual sob o viés do Plano Educacional Individualizado. Projeto de Pesquisa FAPERJ-ACR-2019. Rio de Janeiro: Faculdade de Educação. UERJ, 2020a.

MASCARO, Cristina Angélica Aquino de Carvalho. Protocolo para aplicação do PEI. Material de aula do Curso de Extensão UERJ: alfabetização e letramento sob o viés do Plano Educacional Individualizado. Rio de Janeiro: Faculdade de Educação. UERJ, 2020b.

MASCARO, Cristina Angélica Aquino de Carvalho. Plano Educacional Individualizado: acessibilidade na aprendizagem. Material de aula do Curso de Extensão UERJ: Alfabetização e letramento sob o viés do Plano Educacional Individualizado. Rio de Janeiro: Faculdade de Educação. UERJ, 2021.

PEREIRA, Débora Mara. Análise dos efeitos de um plano educacional individualizado no desenvolvimento acadêmico e funcional de um aluno com Transtorno do Espectro do Autismo, 2014. Tese (Mestrado em Educação) - Centro de 
Educação, Universidade Federal do Rio Grande do Norte, Natal/RN, 2014. Disponível em: https://repositorio.ufrn.br/ jspui/bitstream/123456789/14582/1/DeboraMP_DISSERT.pdf. Acesso em: 17 jan. 2021.

PLETSCH, Márcia Denise; GLAT, Rosana. A escolarização de alunos com deficiência intelectual: uma análise da aplicação do Plano de Desenvolvimento Educacional Individualizado. Linhas Críticas, Brasília, DF, v. 18, n. 35, p. 193-208, jan./abr. 2012.

SANTOS, Boaventura de Sousa. A cruel pedagogia do vírus: o futuro começa hoje. Coimbra: Edições Almedina, abril 2020. p. 32.

SOARES, Magda. Alfaletrar: toda criança pode aprender a ler e a escrever. São Paulo: Editora Contexto, 2020.

Data da submissão: 15/05/2021

Data do aceite: 07/07/2021

\section{ANEXO I}

\begin{tabular}{|l|l|}
\hline \multicolumn{2}{|c|}{ INVENTÁRIO AVALIATIVO } \\
\hline PEI número: & Vigência: \\
\hline Participante: & Pesquisador/Professor: \\
\hline
\end{tabular}

\section{Matriz de Habilidades}

\begin{tabular}{|c|c|c|}
\hline Habilidades & Descritores & Categorização \\
\hline \multicolumn{3}{|l|}{ Aquisição do sistema de escrita } \\
\hline $\begin{array}{l}\text { 1. Compreensão das diferenças existentes } \\
\text { entre os sinais do sistema de escrita } \\
\text { alfabético-ortográfico e outras formas } \\
\text { gráficas e sistemas de representação. }\end{array}$ & $\begin{array}{l}\text { Distinções entre: letras e números, sinais } \\
\text { do sistema de escrita alfabético-ortográ- } \\
\text { fico, marcas ou sinais gráficos ou outros } \\
\text { sistemas de representação. }\end{array}$ & \\
\hline 2. Conhecimento do alfabeto. & $\begin{array}{l}\text { Identificação das letras do alfabeto. } \\
\text { Distinção entre as letras de imprensa } \\
\text { maiúscula e minúscula, e a cursiva, } \\
\text { maiúscula e minúscula. }\end{array}$ & \\
\hline $\begin{array}{l}\text { 3. Domínio de convenções gráficas: orien- } \\
\text { tação da escrita; alinhamento da escrita; } \\
\text { segmentação dos espaços em branco e } \\
\text { pontuação. }\end{array}$ & $\begin{array}{l}\text { Reconhecimento: } \\
\text { Entre a direção correta da escrita (esquerda/ } \\
\text { direita, de cima/para baixo) e utilização } \\
\text { correta da folha (pautada ou não, de acordo } \\
\text { com o planejamento pedagógico); } \\
\text { Das formas gráficas destinadas a marcar a } \\
\text { segmentação na escrita (espaçamento entre } \\
\text { palavras e pontuação). }\end{array}$ & \\
\hline
\end{tabular}




\begin{tabular}{|c|c|c|}
\hline Habilidades & Descritores & Categorização \\
\hline $\begin{array}{l}\text { 4. Reconhecimento de palavras e unidades } \\
\text { fonológicas ou segmentos sonoros. }\end{array}$ & $\begin{array}{l}\text { Identificação de: } \\
\text { Rimas, as sílabas e os sons existentes no início, } \\
\text { no meio e no final de palavras compostas } \\
\text { com sons semelhantes e diferentes; } \\
\text { Segmentação oral de palavras em sílabas; } \\
\text { Segmentação oral de frases em palavras. }\end{array}$ & \\
\hline $\begin{array}{l}\text { 5. Domínio de relações entre grafemas e } \\
\text { fonemas. }\end{array}$ & $\begin{array}{l}\text { Utilização dos princípios e as regras ortográ- } \\
\text { ficas do sistema de escrita, considerando: } \\
\text { As correspondências entre grafemas e } \\
\text { fonemas que são invariáveis, como P, B, } \\
\text { V. F, por exemplo; } \\
\text { As correspondências que dependem do } \\
\text { contexto (regulares contextuais), ou } \\
\text { seja, em que se define, por exemplo, o } \\
\text { valor sonoro da letra considerando a } \\
\text { sua posição na sílaba ou na palavra e os } \\
\text { "sons" que vêm antes e/ou depois. Um } \\
\text { exemplo: a letra S, no início de palavra, } \\
\text { representa sempre o fonema /s/, como } \\
\text { em SAPO; a mesma letra, na posição } \\
\text { entre vogais, representa o fonema /z/ } \\
\text { como em CASA. }\end{array}$ & \\
\hline \multicolumn{3}{|l|}{ LEITURA } \\
\hline $\begin{array}{l}\text { 6. Leitura e compreensão de palavras } \\
\text { compostas por sílabas canônicas e não } \\
\text { canônicas. }\end{array}$ & $\begin{array}{l}\text { Leitura de palavras compostas por dife- } \\
\text { rentes estruturas silábicas, considerando-se } \\
\text { as disposições de consoante }(\mathrm{C}) \text { e vogal (V): } \\
\text { CV - padrão silábico canônico: (ex: sí-la-ba); } \\
\text { V - (ex: a-ba-ca-te); } \\
\text { CVC - (ex: tex-to, ve-ri-fi-car); } \\
\text { CCV - (ex: pa-la-vra). }\end{array}$ & \\
\hline 7. Leitura de frases. & $\begin{array}{l}\text { Compreensão de frases com estrutura } \\
\text { sintática simples (ex: "O rapaz estudou } \\
\text { muito ontem"). }\end{array}$ & \\
\hline $\begin{array}{l}\text { 8. Compreensão global de um texto lido, } \\
\text { com a identificação do assunto principal. }\end{array}$ & $\begin{array}{l}\text { Identificação do assunto de que trata um } \\
\text { texto. }\end{array}$ & \\
\hline $\begin{array}{l}\text { 9. Identificação de diferenças entre } \\
\text { gêneros textuais. }\end{array}$ & $\begin{array}{l}\text { Utilização de diferentes estratégias de } \\
\text { leitura adequadas ao gênero textual e ao } \\
\text { suporte em que o texto é veiculado, bem } \\
\text { como se há utilização de conhecimentos } \\
\text { sobre diferentes gêneros de textos para } \\
\text { localizar informações. }\end{array}$ & \\
\hline \multicolumn{3}{|l|}{ Escrita e produção de textos } \\
\hline 10. Escrita de palavras de cor. & $\begin{array}{l}\text { Escrita de cor de palavras como o } \\
\text { próprio nome e de seus colegas, parentes, } \\
\text { o nome da escola, local de estudo ou } \\
\text { trabalho, o nome da cidade, bairro... }\end{array}$ & \\
\hline $\begin{array}{l}\text { 11. Escrita de palavras com grafia } \\
\text { desconhecida. }\end{array}$ & $\begin{array}{l}\text { Escrita "ditada”, para avaliar a habilidade } \\
\text { de decodificação. Considerar o contexto } \\
\text { da Psicogênese e Sociolinguístico. }\end{array}$ & \\
\hline
\end{tabular}




\begin{tabular}{|c|c|c|}
\hline Habilidades & Descritores & Categorização \\
\hline 12. Escrita de sentenças. & $\begin{array}{l}\text { Escrita com maior ou menor extensão } \\
\text { (quanto maior a extensão, maior a dificul- } \\
\text { dade, pela sobrecarga de atenção e pelo } \\
\text { esforço motor). Considerar o contexto } \\
\text { da Psicogênese e Sociolinguístico. }\end{array}$ & \\
\hline 13. Recontagem de narrativas lidas. & $\begin{array}{l}\text { Reprodução oral ou escrita de textos } \\
\text { lidos em voz alta. Considerar o contexto } \\
\text { da Psicogênese e Sociolinguístico. }\end{array}$ & \\
\hline $\begin{array}{l}\text { 14. Redação de textos curtos adequados: } \\
\text { ao gênero; } \\
\text { ao objetivo; } \\
\text { ao destinatário; } \\
\text { às convenções gráficas apropriadas; } \\
\text { às convenções ortográficas. }\end{array}$ & $\begin{array}{l}\text { Produção, com maior ou menor adequação, } \\
\text { de textos levando em conta a situação de } \\
\text { produção e a situação em que será lido. } \\
\text { Considerar o contexto da Psicogênese e } \\
\text { Sociolinguístico. }\end{array}$ & \\
\hline \multicolumn{3}{|l|}{ Alfabetização matemática } \\
\hline $\begin{array}{l}\text { 15. Noção de conceitos de: cor, tamanho, } \\
\text { forma geométrica, lateralidade, sucessor } \\
\text { e antecessor. }\end{array}$ & $\begin{array}{l}\text { Atividades contextualizadas o conheci- } \\
\text { mento dos conceitos para identificação } \\
\text { do nível de conhecimento e necessidade } \\
\text { de intervenções (priorizar de acordo } \\
\text { com o contexto, o que será avaliado } \\
\text { primeiro) }\end{array}$ & \\
\hline $\begin{array}{l}\text { 16. Conhecimento dos números no } \\
\text { contexto social. }\end{array}$ & $\begin{array}{l}\text { Reconhecimento do nome e o desenho } \\
\text { dos números, por meio de situações } \\
\text { hipotéticas cotidianas (idade, número } \\
\text { do calçado, número da casa, dentre } \\
\text { outros). }\end{array}$ & \\
\hline 17. Noção de quantidade e número. & $\begin{array}{l}\text { Verificação por meio de situações } \\
\text { problema se há conhecimento da relação } \\
\text { entre a quantidade e o desenho do } \\
\text { número. }\end{array}$ & \\
\hline $\begin{array}{l}\text { 18. Realização de cálculos envolvendo as } \\
\text { quatro operações e utilizar os algoritmos. }\end{array}$ & $\begin{array}{l}\text { Verificação do entendimento do conceito } \\
\text { das quatro operações ao realizar } \\
\text { pequenos cálculos, dentro do contexto } \\
\text { individual. Selecionar as operações } \\
\text { que forem avaliadas. Utilizar também } \\
\text { instrumentos como calculadora e mate- } \\
\text { rial concreto, caso a situação se adeque } \\
\text { ao uso. }\end{array}$ & \\
\hline 19. Identificação do valor do dinheiro. & $\begin{array}{l}\text { Verificação, por meio de situações } \\
\text { didáticas contextualizadas, se entende } \\
\text { conceitos: caro, barato, muito dinheiro, } \\
\text { pouco dinheiro... dentre outros... }\end{array}$ & \\
\hline $\begin{array}{l}\text { 20. Manuseio de dinheiro: agrupamento } \\
\text { e distribuição de valores para paga- } \\
\text { mentos e trocos. }\end{array}$ & $\begin{array}{l}\text { Verificação em situação real do manu- } \\
\text { seio de notas e moedas para seleção do } \\
\text { valor adequado para pagamento e confe- } \\
\text { rência de troco. }\end{array}$ & \\
\hline $\begin{array}{l}\text { 21. Identificação do dia da semana, mês, } \\
\text { ano. }\end{array}$ & $\begin{array}{l}\text { Verificação, com instrumentos reais e } \\
\text { atividades do cotidiano, se há domínio } \\
\text { de localização temporal. }\end{array}$ & \\
\hline
\end{tabular}




\begin{tabular}{|l|l|l|}
\hline Habilidades & Descritores & Categorização \\
\hline 22. Reconhecimento de horas. & $\begin{array}{l}\text { Verificar se há reconhecimento da } \\
\text { divisão do dia em horas minutos e da } \\
\text { necessidade de organização do cotidiano } \\
\text { com base nos horários; assim como } \\
\text { a habilidade para consulta de instru- } \\
\text { mentos que informem as horas. Fazer } \\
\text { atividades dentro da rotina pessoal. }\end{array}$ & \\
\hline $\begin{array}{l}\text { Obs: Cada uma das habilidades poderá ser subdividida em outras, que o pesquisador/professor julgar necessário } \\
\text { serem incluídas. Caso se desdobre, por exemplo, uma habilidade oriunda da número 05, a habilidade acrescentada } \\
\text { deverá ser pontuada como: 5.1; 5.2; e, assim, sucessivamente. }\end{array}$ \\
\hline
\end{tabular}

$\rightarrow$ A avaliação do participante, em todas as etapas, será pontuada, após realização de situações didáticas no formulário de elaboração de atividades, por meio da escala abaixo:

\begin{tabular}{|l|c|l|c|}
\hline Categorização & Sigla & Critério de inclusão & Pontuação \\
\hline Realiza independente & RI & Não requer nenhuma ajuda & 3 \\
\hline Realiza parcialmente & RP & Requer pouca ajuda & 2 \\
\hline Realiza com apoio & RA & Não realiza sem ajuda física ou de suporte & 0,5 \\
\hline Não Realiza & NR & $\begin{array}{l}\text { Não consegue, mesmo com ajuda física ou } \\
\text { de suporte }\end{array}$ & 0 \\
\hline Não foi apresentado & NA & Não houve atividade & 0 \\
\hline
\end{tabular}

Quadro 01: Escala de avaliação (MASCARO, 2020). 